\title{
Strategi Kepala Sekolah Dalam Peningkatan Mutu Akademik Dan Non Akademik Peserta Didik
}

\author{
Riska Nur Fitriana ${ }^{1}$, Warih Handayaningrum², Maria Veronika Roesminingsih ${ }^{3}$ \\ ${ }^{123}$ Surabaya State University \\ Email: riska.19003@mhs.unesa.ac.id
}

\begin{abstract}
In its management, schools need quality assurance as a benchmark for assessing the success or failure of educational institutions. One of the most important aspects that affect the quality of education is leadership and quality management. The research objectives are: (1) to describe how the principal's strategy in improving the academic quality of students at SMAN 2 Sidoarjo (2) to describe how the principal's strategy is to improve the non-academic quality of students at SMAN 2 Sidoarjo. This study uses a qualitative descriptive. Collecting data using the method of observation, interviews and documentation. The results of this study are: (1) the principal's strategy in improving the academic quality of students at SMAN 2 Sidoarjo is through the PPDB process carried out in 4 stages, supervising the learning process in order to know the achievements in the learning process, taking a good personal approach with all school stakeholders, excellent programs (Academic Skills) that can support students to continue to work and produce achievements. develop school planning as much as possible, analyze the challenges, obstacles and future opportunities that will be faced by SMAN 2 Sidoarjo (2) the principal's strategy in improving the non-academic quality of students at SMAN 2 Sidoarjo is a superior program of life skills in the form of learning to be able to survive in life, more productive and supported by existing programs in schools. Social Skill with the hope of being able to socialize in society. Develop school planning as much as possible, analyze the challenges, obstacles and future opportunities that will be faced by SMAN 2 Sidoarjo.
\end{abstract}

Keywords: Principal's strategy, Quality Improvement, Academic, Non Academic

\begin{abstract}
Abstrak
Dalam pengelolaannya, sekolah membutuhkan penjaminan mutu sebagai tolak ukur menilai keberhasilan atau kegagalan lembaga pendidikan. Salah satu aspek terpenting yang mempengaruhi kualitas pendidikan adalah kepemimpinan dan manajemen mutu. Tujuan penelitian adalah: (1) mendeskripsikan bagaimana strategi kepala sekolah dalam peningkatan mutu akademik peserta didik di SMAN 2 Sidoarjo (2) mendeskripsikan bagaimana strategi kepala sekolah dalam peningkatan mutu non akademik peserta didik di SMAN 2 Sidoarjo. Penelitian ini menggunakan deskriptif kualitatif. Pengumpulan data menggunakan metode observasi, wawancara dan dokumentasi. Hasil penelitian ini adalah: (1) strategi kepala sekolah dalam peningkatan mutu akademik peserta didik di SMAN 2 Sidoarjo adalah dengan melalui Proses PPDB dilakukan dalam 4 tahap, melakukan pengawasan terhadap proses pembelajaran agar mengetahui capaian dalam proses pembelajaran, melakukan pendekatan personal yang baik dengan seluruh stakeholder sekolah, progam unggulan (Akademic Skill) yang dapat menunjang peserta didik untuk terus berkarya dan menghasilkan prestasi. menyusun perencanaan sekolah dengan semaksimal mungkin, menganalisa tantangan, hambatan serta peluang kedepan yang akan dihadapi oleh SMAN 2 Sidoarjo (2) strategi kepala sekolah dalam peningkatan mutu non akademik peserta didik di SMAN 2 Sidoarjo adalah Progam unggulan life skill berupa pembelajaran agar mampu survive dalam kehidupan, lebih produktif dan didukung oleh progam yang ada di sekolah. Social Skill dengan harapan mampu bersosialisasi dalam masyarakat. Menyusun perencanaan sekolah dengan semaksimal mungkin, menganalisa tantangan, hambatan serta peluang kedepan yang akan dihadapi oleh SMAN 2 Sidoarjo.
\end{abstract}

Kata Kunci: Strategi Kepala Sekolah, Peningkatan Mutu, Akademik, Non Akademik

\section{PENDAHULUAN}

Pendidikan merupakan salah satu pilar yang penting untuk meningkatkan kualitas sumber daya manusia. Pendidikan yang bermutu merupakan harapan setiap masyarakat. Pengalaman menunjukkan bahwa modal kehidupan dalam setiap perubahan zaman adalah pendidikan. Pendidikan merupakan kunci utama bagi suatu bangsa untuk menyiapkan masa depan yang lebih baik. Oleh karena itu, pendidikan dan semua elemen yang terkait didalamnya harus diberdayakan ke arah pencapaian tujuan penciptaan sumber daya manusia (SDM) semaksimal mungkin sehingga berkualitas.

Tilaar (2008:208) Pendidikan merupakan sebagian dari kehidupan masyarakat dan juga sebagai dinamisator masyarakat itu sendiri. Menurut Idhoci Anwar (2013:29) Sebagaimana yang telah terjadi pada dunia 
produksi pada umumnya, kepedulian akan mutu produk pendidikan pun didorong oleh persoalan dasar, bagaimana mengintegrasikan semua fungsi dan proses dalam suatu organisasi agar tercapai peningkatan mutu secara berkelanjutan.

Mulyoto (2013:199) Negara tidak hanya mengamanahkan sebuah kecerdasan intelektual saja, akan tetapi juga kekayaan moral dan budi pekerti setiap warga negaranya juga diwajibkan. Untuk itu perlu adanya sebuah system pendidikan yang baik dan berkualitas di sekolah. Sekolah sebagai suatu lembaga Pendidikan menghadapi dua tuntutan yaitu tuntutan dari masyarakat dan tuntutan dunia usaha. Hal yang menjadi tuntutan yaitu tentang masalah rendahnya mutu pendidikan dan masalah relevansi terhadap perkembangan kebutuhan masyarakat di era industrialisasi dan globalisasi yang semakin terbuka.

Tuntutan yang pertama yakni mengenai mutu pendidikan merupakan hal yang wajib dan harus menjadi prioritas utama. Jika sebuah pendidikan mempunyai mutu yang baik secara otomatis akan mampu menjawab permasalahan atau tuntutan yang kedua yakni mengenai masalah relevansi terhadap sebuah perkembangan kebutuhan masyarakat yang terjadi di era globalisasi dan industrialisasi dewasa ini.

Dalam pengelolaannya, sekolah membutuhkan penjaminan mutu sebagai tolak ukur menilai keberhasilan atau kegagalan lembaga pendidikan. Salah satu aspek terpenting yang mempengaruhi kualitas pendidikan adalah kepemimpinan dan manajemen mutu. Tujua manajemen mutu adalah untuk memelihara dan meningkatkan kualitas pendidikan secara berkelanjutan yang dilakukan secara sistematik untuk memenuhi kebutuhan stakeholders.

Kepala sekolah bertanggung jawab dalam semua kegiatan di sekolah. Namun sekarang banyak kepala sekolah yang kurang berkompeten dalam melakukan manajemen sekolahnya. Misalnya kurang tegasnya kepala sekolah dalam melakukan pengambilan keputusan dalam menanggapi suatu masalah yang ada di sekolah dan kurang kreatifnya kepala sekolah dalam memberikan pembaharuan di sekolah.
Richard. A. Gorton

Pemimpin pendidikan merupakan sosok yang mengorganisasikan sumber-sumber daya intasi dan sumber daya fisik untuk mencapai tujuan organisasi pendidikan secara efektif dan efisien. Peran utamanya adalah mengembangkan dan mengimplementasikan prosedur dan kebijaksanaan pendidikan yang dapat menghasilkan efisiensi pelaksanaan pendidikan.

Dekdipnas (2007:768) kualitas pendidikan dapat diukur dengan standar nasional pendidikan yaitu standar isi, standar lulusan, standar kompetensi, standar pendidikan dan tenaga kependidikan, srana dan prasarana, standar pengelolaan, standar pembiayaan dan standar penilaian pendidikan.

Mulyadi (2010:71) dalam usaha meningkatkan mutu sekolah suatu lembaga juga berupaya meningkatkan mutu lulusan, karena tidak mungkin jika lulusan bermutu tanpa didasari proses pendidikan yang bermutu. Sifat dari mutu adalah global, menyeluruh yang menyangkut semua komponen pelaksanaan dan kegiatan pendidikan.

Dasim Budimansyah (2008:56) Salah satu upaya konkret untuk mendongkrak mutu pendidikan adalah dengan penguatan partisipasi masyarakat, dengan mengakomodasi pandangan, aspirasi, dan menggali potensi masyarakat untuk menjamin demokratisasi, transparansi, dan akuntabilitas. Fahmi Rozi (2020:59) Partisipasi masyarakat itu dinilai penting, karena merupakan salah satu realisasi dari esensi demokrasi berkeadilan, maka dibentuklah lembaga sebagai wadah masyarakat untuk berparsipasi meningkatkan mutu sekolah yang disebut dengan komite sekolah.

Pendidikan yang bermutu meliputi input, proses dan output. Arcaro (2005:75) yang mengatakan bahwa mutu adalah sebuah proses terstruktur untuk memperbaiki keluaran yang dihasilkan. Selanjutnya di kemukakan bahwa untuk memperoleh mutu baikdalam pendidikan di perlukan kerjasama antar pendidik, orang tua, pejabat pemerintah, wakilwakil masyarakat dan pemuka bisnis guna memberikan kepada siswa sumberdaya yang dibutuhkan untuk memnuhi tantangan masyarakat, bisnis dan akademik sekarang dan masa depan. 
Tirtahardja dan Sulo (2005:232) menyatakan bahwa mutu pendidikan secara jelas dapat dilihat dari kualitas lulusan. Mutu pendidikan dapat tercapai apabila sistem pendidikan telah dapat melalui proses pendidikan yang bermutu yang mengedepankan mendidik anak agar memiliki etos belajar dan kerja keras, memiliki visi kebangsaan, komitmen kemanusiaan serta etos keilmuan yang kuat sehingga akan dihasilakn lulusan bermutu, baik dari segi pengetahuan, keterampilan, pembentukan karakter berwawasan kebangsaan dan kemanusiaan tanpa harus mengabaikan kejujuran dan objektivitas.

Ajrianto (Faktor yang menentukan mutu pendidikan ditentukan oleh faktor input dan faktor proses. Faktor input meliputi siswa, kurikulum, bahan ajar, strategi pembelajaran, sarana pembelajaran di sekolah, dukungan administrasi, dan prasarana sekolah. Sedangkan faktor proses meliputi penciptaan suasana yang kondusif, koordinasi proses pembelajaran, interaksi antar unsur-unsur di sekolah, baik guru dengan guru, siswa dengan siswa, maupun guru dan staf administrasi sekolah, dalam akademis meliputi akademik dan non akademik. Konteks mutu bisa dilihat dari prestasi yang dicapai dalam bidang akademik maupun non akademik. Selain itu indicator yang dijadikan ukuran mutu seperti kedispilinan, tanggung jawab, saling menghormati dan kenyamanan di sekolah.

SMAN 2 Sidoarjo merupakan salah satu sekolah negeri di Sidoarjo. Tepatnya berada di Jl. Raya Lingkar Barat Gading Fajar 2 Sidoarjo. Keunikan yang membedakan sekolah ini dengan sekolah lain adalah peningkatan progam, karena tidak semua sekolah mempunyai inovasi untuk meningkatkan kualitas peserta didik apalagi dimasa pandemic, diantara progam-progamnya seperti Learning and Teaching, kelas percepatan, kelas kategori, progam HALAL (Hafal Al-Qur'an), progam OMPA (Orang Tua Peduli Anak), Progam ORI (Orasi Ilmiah), dan Progam JAKA (Jalinan Kerja sama Alumni).

Trobosan dan upaya yang dilakukan kepala sekolah dalam peningkatan mutu pendidikan diantaranya Penerapan pembelajaran kontekstual dengan memanfaatkan komputer dan teknologi informasi, majalah yang berisi informasi-informasi SMAN 2 Sidoarjo yang mana informasi tersebut diataranya kegiatan kesiswaan, kehumasan dan keagamaan dan kegiatan pengembangan hasil belajar, Selain itu dalam proses pembelajaran di kelas beberapa kelas sudah menggunakan teknologi komputer dan LCD. Disisi lain kepala sekolah dalam menjalankan kepemimpinannya selalu terbuka sehingga mampu menggerakkan para guru, murid dan warga sekolah untuk selalu meningkatkan mutu pendidikan di SMAN 2 Sidoarjo sehingga para siswa mempunyai prestasi akademik dan non akademik. Berdasarkan uraian tersebut penulis akan membahas penelitian tentang (1) bagaimana strategi kepala sekolah dalam peningkatan mutu akademik peserta didik di SMAN 2 Sidoarjo? (2) bagaimana strategi kepala sekolah dalam peningkatan mutu non akademik peserta didik di SMAN 2 Sidoarjo?

\section{METODE}

Jenis penelitian ini termasuk deskriptif kualitatif. Lokasi Penelitian ini berada di SMAN 2 Sidoarjo, di Jl. Lingkar Barat Gading Fajar 2 Sidoarjo Di dalam penelitian ini sumber data primer adalah kepala sekolah. Sumber data sekunder adalah data sekolah, data prestasi sekolah atau dokumen lainnya yang diperlukan. . Pengumpulan data melalui Observasi dipakai untuk mengumpulkan data terkait strategi apa yang ditempuh kepala sekolah dalam peningkatan mutu. Subjek yang diamati adalah kepala sekolah, wakasek, guru, siswa, karyawan, bagaimana sikap perilaku mewujudkan tujuan yang ingin dicapai. Wawancara atau Interview ini ditujukan kepada kepala sekolah atau waka kurikulum, humas, guru di SMAN 2 Sidoarjo. Dokumentasi terkait dokumen perencanaan, arsip nilai, perangkat pembelejaran, pedoman pelaksanaan kerja buku panduan pelaksanaan pendidikan, arsip siswa yang diterima di PTN, arsip prestasi siswa dalam mengikuti lomba. Teknik analisis data menggunakan reduksi data, penyajian data, dan penarikan keismpulan.

\section{HASIL DAN PEMBAHASAN}

Berdasarkan hasil wawancara dan observasi yang dilakukan oleh penulis di SMAN 2 
Sidoarjo pada kepala sekolah. Hasil penelitian berdasarkan ketiga teknik pengambilan data tersebut dipaparkan sebagai berikut:

a. Strategi Kepala Sekolah Dalam Peningkatan Mutu Akademik

Pertama, Proses penerimaan peserta didik baru (PPDB). Proses PPDB di SMAN 2 Sidoarjo dilakukan dalam 4 tahap dengan tujuan untuk mengetahui kualitas yang sesuai dengan kebijakan sekolah, seakligus menentukan kelas kategori. Tes pertama tes akademik, kedua tes psikotes, ketiga tes tahsin dan keempat wawancara.

Kedua, Kepala sekolah melakukan pengawasan terhadap proses pembelajaran agar mengetahui capaian dalam proses pembelajaran, mengadakan evaluasi terhadap visi misi yang telah berjalan apakah sudah tercapai dan seberapa persen ketercaaian dari visi,misi yang telah dibuat,melihat proses pembelajaran siswa dan mengukur prestasi yang telah dicapai.

Strategi ini dilakukan untuk mencapai tujuan dari visi,misi dan tujuan sekolah untuk menuju sekolah unggul dalam hal lain dengan adanya strategi yang telah di rancang oleh kepala sekolah dan guru maka akan mempermudah jalannnya kegiatan apapun.

Ketiga, Kepala sekolah melakukan pendekatan personal yang baik dengan seluruh stakeholder sekolah. Dengan pendekatan yang baik tersebut, kepala sekolah dapat dengan mudah membimbing guru, tenaga kependidikan, siswa di sekolah untuk menjalankan tugas dan tanggung jawabnya masing-masing dengan strategi ini, kepala sekolah dapat menjalin hubungan yang baik dengan seluruh stakeholder di sekolah tersebut, tanpa mengurangi wibawanya sebagai seorang kepala sekolah Oleh karena itu upaya yang dapat dilakukan kepala sekolah dalam meningkatkan kinerjanya sebagai edukator, khususnya dalam peningkatan kinerja tenaga kependidikan dan prestasi belajar peserta didik adalah mengikutsertakan guru-guru dalam pendidikan lanjutandengan cara mendorong para guru untuk memulai kreatif dan berprestasi.
Kemudian, stragtegi kepala sekolah SMAN 2 Sidoarjo dalam upaya meningkatkan mutu pendidikan di SMAN 2 Sidoarjo adalah dengan menyusun perencanaan sekolah dengan semaksimal mungkin, menganalisa tantangan, hambatan serta peluang kedepan yang akan dihadapi oleh SMAN 2 Sidoarjo dalam upaya meningkatkan mutu pendidikannya. Dalam menyusun perencanaan sekolah, kepala sekolah SMAN 2 Sidoarjo selalu melibatkan seluruh stakeholder sekolah dan menjalinkoordinasi dalam melaksanakan kegiatan yang telah ditetapkan sebagai program sekolah. Selain itu, kepala sekolah SMAN 2 Sidoarjo berupaya untuk selalu meningkatkan fungsi pengawasannya, melakukan evaluasi terhadap kegiatan, mengadakan rapat yang baik terjadwal maupun yang tidak terjadwal, dan menjalankan seluruh tugas tanggungjawabnya bersama-sama dengan seluruh stakeholder sekolah. Sebagaimana yang dikemukakan oleh Sabirin (2012) bahwa kepala sekolah sebagai manajer, mempunyai fungsi:menyusun perencanaan, mengkoordinasikan kegiatan, melakukan pengawasan, melakukan evaluasi terhadap kegiatan, mengadakan rapat, mengambil keputusan, mengatur proses pembelajaran, mengatur administrasi, dan mengatur tata usaha, siswa, ketenagaan, sarana, dan prasarana, keuangan.

Keempat, progam unggulan (Akademic Skill), dengan adanya progam ini maka dapat menunjang peserta didik untuk terus berkarya dan menghasilkan prestasi. Salah satunya yaitu Learning and Teaching (belajar mengajar), pada siswa fokus belajar dan guru fokus mengajar, dalam megajar guru harus mempunyai target. Di dalam sebuah lembaga pasti mempunyai target nilai atau biasa disebut KKM maka seorang guru harus mempunyai target sendiri, dalam arti target guru tersebut harus diatas target lembaga. Namun jika ada siswa yang tidak mencapai target guru tersebut maka guru harus mengevaluasi apa yang kurang dari pembelajaran tersebut. 
Kelas Percepatan, siswa yang mempunyai kemampuan lebih akan masuk di kelas percepatan dengan waktu hanya 2 tahun. Ketiga adalah progam kategori, progam yang baik adalah progam yang mempuyai lanjutan atau arah. Setelah learing and teaching maka ada kelas kategori dimana siswa akan disesuaikan berdasarkan kemampuan mereka. Kelas kategori, dimana di awal pendaftaran masuk sekolah ada nilai pretest nya yang akan digunakan untuk pembagian kelas. Tidak hanya itu, pembagian kelas itu selalu diroling tiap semester dengan memakai nilai harian dan UAS. Kelas percepatan atau kelas progam 2 tahun untuk peserta didik yang mempunyai nilai unggul dari yang lain, sebelum ditetapkan di kelas ini peserta didik beserta orang tua selalu diajak berdiskusi terlebih dahulu. Karena misal seorang murid tersebut mempunyai unggul yang lebih terkadang tidak mau untuk ikut kelas percepatan dengan alas an tertentu. Jadi pihak sekolah selalu melibatkan orang tua murid untuk persetujuannya. Tes kejuruan untuk masuk ke perguuan tinggi, disini siswa dikelompokkan dengan pemilihan jurusan yang sama dalam satu sekolah dan nilai yang didapat harus rangking 1 dan 2 artinya jika siswa tersebut perangkingannya lebih dari itu maka harus lebih giat belajar dan ini juga mengikutsertakan orangtua untuk memotivasi anaknya agar lebih giat jika memang serius untuk memilih jurusan tersebut di perguruan tinggi. Dan terakhir progam progam tahfid (tes baca tulis $\mathrm{Al}$ Qur'an).

b. Strategi Kepala Sekolah Dalam Peningkatan Mutu Non Akademik

Progam unggulan life skill berupa pembelajaran agar mampu survive dalam kehidupan, lebih produktif dan didukung oleh progam yang ada di sekolah . Social Skill merupakan kemampuan dalam bersosialisasi dalam masyarakat. Salah satu progamnya adalah progam unggulan $O M P A$ (Orang Tua Peduli Anak) salah satu orang tua dari siswa di datangkan di kelas untuk memberi nasihat atau apa saja yang berhubungan dengan kasih sayang orang pada anak. Progam unggulan ORI (Orasi Ilmiah) siswa belajar public speaking. Progam unggulan JAKA (Jalinan Kerja sama Alumni) alumni yang berhasil didatangkan ke sekolah untuk memberi motivasi kepada siswa.

Stragtegi kepala sekolah SMAN 2 Sidoarjo dalam upaya meningkatkan mutu pendidikan di SMAN 2 Sidoarjo adalah dengan menyusun perencanaan sekolah dengan semaksimal mungkin, menganalisa tantangan, hambatan serta peluang kedepan yang akan dihadapi oleh SMAN 2 Sidoarjo dalam upaya meningkatkan mutu pendidikannya. Dalam menyusun perencanaan sekolah, kepala sekolah SMAN 2 Sidoarjo selalu melibatkan seluruh stakeholder sekolah dan menjalinkoordinasi dalam melaksanakan kegiatan yang telah ditetapkan sebagai program sekolah. Selain itu, kepala sekolah SMAN 2 Sidoarjo berupaya untuk selalu meningkatkan fungsi pengawasannya, melakukan evaluasi terhadap kegiatan, mengadakan rapat yang baik terjadwal maupun yang tidak terjadwal, dan menjalankan seluruh tugas tanggungjawabnya bersama-sama dengan seluruh stakeholder sekolah. Sebagaimana yang dikemukakan oleh Sabirin (2012) bahwa kepala sekolah sebagai manajer, mempunyai fungsi:menyusun perencanaan, mengkoordinasikan kegiatan, melakukan pengawasan, melakukan evaluasi terhadap kegiatan, mengadakan rapat, mengambil keputusan, mengatur proses pembelajaran, mengatur administrasi, dan mengatur tata usaha, siswa, ketenagaan, sarana, dan prasarana, keuangan.

\section{KESIMPULAN}

a. Strategi Kepala Sekolah Dalam Peningkatan Mutu Akademik

Pertama, Proses penerimaan peserta didik baru (PPDB). Proses PPDB di SMAN 2 Sidoarjo dilakukan dalam 4 tahap. Kedua, Kepala sekolah melakukan pengawasan terhadap proses pembelajaran agar mengetahui capaian dalam proses pembelajaran, mengadakan evaluasi terhadap visi misi yang telah berjalan. 
Ketiga, Kepala sekolah melakukan pendekatan personal yang baik dengan seluruh stakeholder sekolah. Keempat, progam unggulan (Akademic Skill) dengan tujuan dapat menunjang peserta didik untuk terus berkarya dan menghasilkan prestasi.

b. Strategi Kepala Sekolah Dalam Peningkatan Mutu Non Akademik

Progam unggulan life skill berupa pembelajaran agar mampu survive dalam kehidupan, lebih produktif dan didukung oleh progam yang ada di sekolah.

Social Skill merupakan kemampuan dalam bersosialisasi dalam masyarakat. Menyusun perencanaan sekolah dengan semaksimal mungkin, menganalisa tantangan, hambatan serta peluang kedepan yang akan dihadapi oleh SMAN 2 Sidoarjo dalam upaya meningkatkan mutu pendidikannya.

\section{DAFTAR PUSTAKA}

A. R. Tilaar. (2018). Manajemen Pendidikan Nasional. Bandung: PT. Remaja Rosdakarya.

Ahmad Fauzi. (2020). Analisis Biaya Mutu Dalam Meningkatkan Daya Saing Pendidikan," Jumpa: Jurnal Manajemen Pendidikan 1(1), 51-62;

Aminol Rosid Abdullah. (2019). Capailah Prestasimu. Depok: Guepedia, 17.

Asep Priatna.(2018). Manajemen Pengembangan Mutu Sekolah. Jurnal Administrasi Pendidikan.25(1),81.

Bakhruddin, M. P. I. M. (2016). Peran Kepala Sekolah Dalam Memberdayakan Tenaga Pendidik (Key Concept of Leadership Roles at SMA Negeri 16 and SMA Muhammadiyah 2, Surabaya). Jurnal Studi Keislaman, 1(1).

Daryanto. (2011). Kepala sekolah sebagai pemimpin pembelajaran. Yogyakarta: Gaya media. 80.

David Firna Setiawan. (2018). Prosedur Evaluasi dan Pembelajaran. Yogjakarta: Deepublish, 256.

Erwin Firdaus. (2021). Manajemen Mutu Pendidikan. Yayasan Kita Menulis.
Fahmi Rozi and Idi Warsah. (2020). Sinergitas Peran Komite dan Kepala Madrasah dalam Meningkat Mutu Pendidikan Di Man 1 Lebong, Bengkulu: Indonesia. Jurnal Manajemen Pendidikan Islam Al-

Hamdan Dimyati. (2014). Manajemen proyek. CV Pustaka Setia. 119.

Idhoci Anwar. (2013). Administrasi Pendidikan dan Manajemen Biaya Pendidikan. Jakarta: PT. Raja Grafindo Persada.

Moh. Saifulloh. (2012). Strategi peningkatan mutu pendidikan di sekolah. Jurnal Sosial Humaniora, Vol 5 No.2, 206.

Moh. Saifulloh.,Zainul M.,\& Hermanto. (2012). Strategi Peningkatan Mutu Pendidikan Di Sekolah. Jurnal Sosial Humaniora., 5(2), 207.

Muhamad Sholeh. (2016). Keefektifan Peran Kepala Sekolah Dalam Meningkatkan Kinerja Guru. Jurnal Dinamika Manajemen Pendidikan 1(1), 41-54

Muhammad Rifai. (2018). Manajemen Peserta Dididk (pengelolaan peserta didik untuk efektivitas pebelajaran). Medan:CV Pusdikra Mitra Jaya, 5.

Mulyadi, (2010). Kepemimpinan Kepala Sekolah Dalam Mengembangkan Budaya Mutu, (Malang:UIN-Maliki Press. 71.

Sitti Nur Halimah, dkk. (2019). Media Sosial dan Masyarakat Pesisir Refleksi Pemikiran Mahasiswa Bidikmisi.Yogjakarta: Deepublish, 59.

Triwahyu Riyatuljannah. (2020). Peran Dan Fungsi Kepala Sekolah Dalam Mewujudkan Sekolah Efektif Di Lingkungan Sekolah Dasar. Journal of Islamic Primary Education, 3 (2), 1-13. 